\title{
The Meaning of Money
}

The first full treatment in nearly a century of what money really does for us and to us. Drawing on materials as varied as immigrant manuals, books on etiquette, and household budget studies, the author shows how people have invented their own forms of currency, differentiating the ways spending and saving take place.

“Zelizer has a genius for detecting hidden order in everyday practices. ... Best of all, she writes of these complex matters with grace, lucidity, wit, and humanity." -CHARLES TILLY, New School for Social Research

"A wonderfully enterprising journey through the roles played by money in consumer life and culture." -ALBERT O. HIRSCHMAN, Institute for Advanced Study

"A landmark book .... a model of rigorous and innovative scholarship, not only for economic sociology but for all of the social sciences." -PIERRE BourdieU, Collège de France

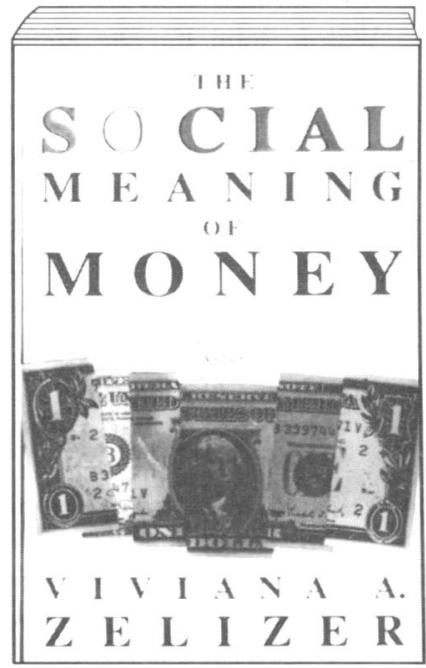

256pp. $\$ 24.00$

\section{What happens when science marries money?}

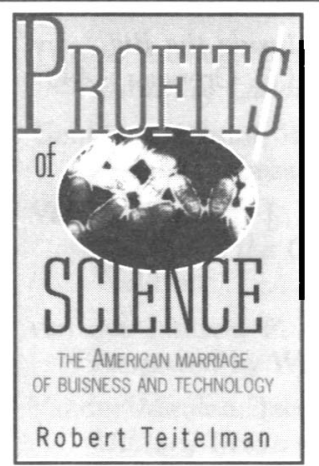

"Recounts some of high technology's greatest war stories in a series of compact narratives .... Fascinating.... A good resource and a pleasure to read." -Michael GianturCO, Wall Street Journal

272pp. $\$ 23.00$

"A provocative and powerful argument for a new industrial reality ... A compelling and fresh perspective on the new role of large companies." -ROSABETH MOSS KANTOR, Harvard University

304pp. $\$ 25.00$

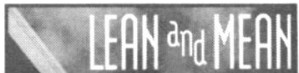

\section{Is bigger better?}



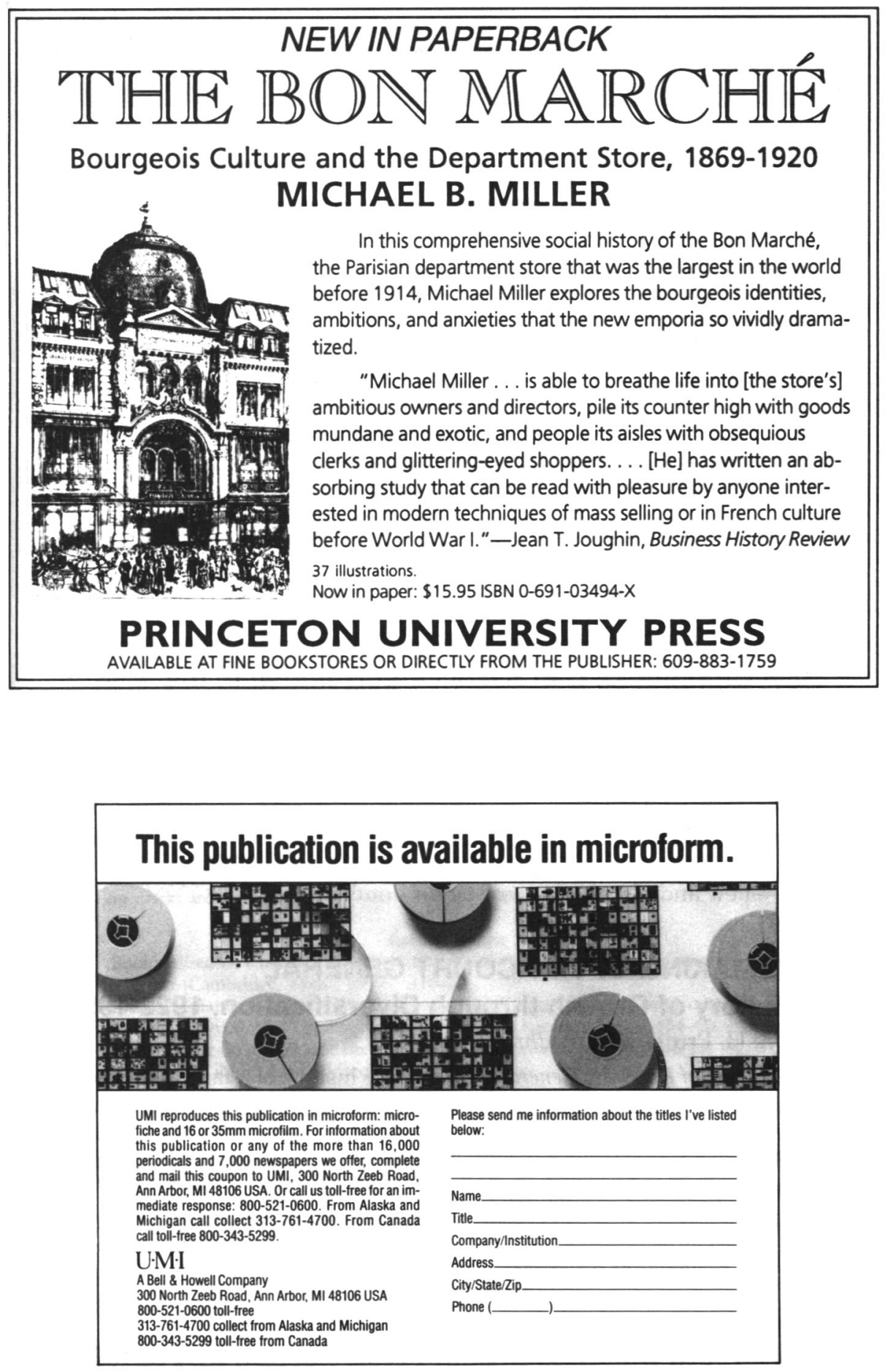


\section{Harvard Business School Press}

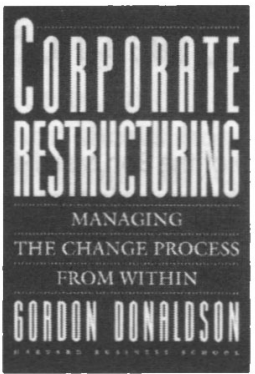

CORPORATE RESTRUCTURING Managing the Change Process from Within

Gordon Donaldson, Harvard Business School

Corporate Restructuring demonstrates why voluntary restructuring provides the best chance for the orderly evolution of the firm and the preservation of its independence. Drawing on examples such as General Mills, Burlington Northern, and CPC International, Donaldson shows how these firms successfully implemented radical change within the normal internal governance system.
$\$ 29.95$
240 pages

\section{MASTERING THE DYNAMICS OF INNOVATION How Companies Can Seize Opportunities in the Face of Technological Change}

James M. Utterback, Massachusetts Institute of Technology

In this engaging book, Utterback draws on the rich history of innovation by inventors and entrepreneurs-ranging over a wide spectrum of industries-to develop a practical model for how innovation enters an industry, how mainstream firms typically respond, and how--over time-new and old players wrestle for dominance.

$\$ 24.95$

256 pages

\section{THE MAKING OF HARCOURT GENERAL}

\section{A History of Growth through Diversification, 1922-1992}

Bettye H. Pruitt, The Winthrop Group

The Making of Harcourt General is a valuable history of a family-owned proprietorship which grew into a multibillion dollar diversified firm. Pruitt traces the growth of the company that started in the 1930s as a small regional theater chain, and, by the early 1970s, emerged as General Cinema Corporation, the largest national theater chain of its time.

320 pages, with 16 pages of photographs

Available at bookstores, or call 1-800-545-7685 ext. 641A/

$$
\text { 617-4 95-6192 ext. 641A }
$$

For a complete catalog of our books, write:

Harvard Business School Press, Boston, MA 02163 


\section{GUIDELINES FOR CONTRIBUTORS}

\section{Geneml Information}

Manuscripts are considered for publication on the understanding that they are not concurrently under consideration elsewhere and that the material-in substance as well as form-has not been previously published.

Three copies of the manuscript should be submitted.

Authors should identify themselves only on a separate title page that provides name, mailing address, and telephone number. Aurhors must also remember not to identify themselves in the body of the manuscript; specifically, references to their own work in the text should be in the third person, and citations should be written without possessive pronouns-not "See my. . . ."

Each article should be accompanied by a précis of 75-100 words outlining the main point(s) of the paper and placing the article in context. Subheads should be used to divide the manuscript into three or four sections (or more, depending on length).

We do not have an upper or lower page limit, but articles usually run between 25 and 60 typescript pages, including notes and other material.

Articles must contain notes in the humanities style, not references as in the social sciences.

We are always cager to publish illustrations, but authors should not include originals of illustrative materials at the time of submission; photocopies of such material may be included.

Authors of accepted manuscripts will receive two copies of the issue in which the article appears and turenty-five tree offprints.

\section{Manuscript Preparation}

ALL material-including extracted quotations and notes-must be double-spaced. Legible photocopies or word-processed originals may be submitted. Use of dot-matrix printers is discouraged.

Notes should be numbered consecutively and citations should be placed at the end of the text Do not place footnotes at the bottom of the page (sec word-processing instructions).

Each table or figure should ncupy a separate page and should be numbered (in arabic numerals) and grouped together between the text and the notes. The position of these items should be indicated in the text (as, "see Table 3"), but they should not be mingled with the text and no extra space should be left for them there. Fach table and figure must be accompanied by a complete source.

We use the 13th edition of The Chicago Manual of Style (1982) and spell and hyphenate words according to Webster's Ninth New' Collegiate Dictionary.

The journal encourages authors to use gender-neutral prose in all cases where it is not anachronistic to do so; male nouns and pronouns should not be used to refer to people of both sexes.

We use the day-month-year form for dates, as 11 Februan 1990.

Double quotation marks should be used for journal titles and direct quotation; single quotation marks are used for quoted material inside quotations.

\section{Sample Citation Forms:}

Book: Alfred D. Chandler, Jr., The Visible Hand: The Managerial Rowlution in American Business (Cambridge, Mass., 1977), 321-22

Journal: Charles Cheape, "Not Politicians but Sound Businessmen: Norton Company and the Third Reich," Business History Review 62 (Autumn 1988): 444-66.

Note that we do not include the publisher in book citations. We do not use loc. cit., op. cit., or idem., but ibid. (not italicized) may be used.

\section{Won-Processing Guidelines}

The jourual can accept disks of all standard sizes and densities, but they must be formatred in MS-DOS; we cannot use Apple or MacIntosh software. WordPerfect is directly compatible, but we may be able to accept your document if it can be converted into an ASCII file.

Potential contributors should submit hard copy, not diskettes, initially, but it will save considerable work for all parties in the event of acceptance if authors working on PCs follow a few rules from the beginning

In general, use as few formatting commands as possible.

Do not justify or half-justify the right-hand margin.

Do not hyphenate words at the end of lines.

Do not use hard returns except for new paragraphs or required page ends except as absolutely necessary (for example, to break between text and notes).

Do not use special fonts; underline material that is to be set in italics.

Most important, do not use the word processor's automatic footnote functions: do not embed notes in the text. Notes should be keyed in at the end of the text (after any tables) or as a separate file. 


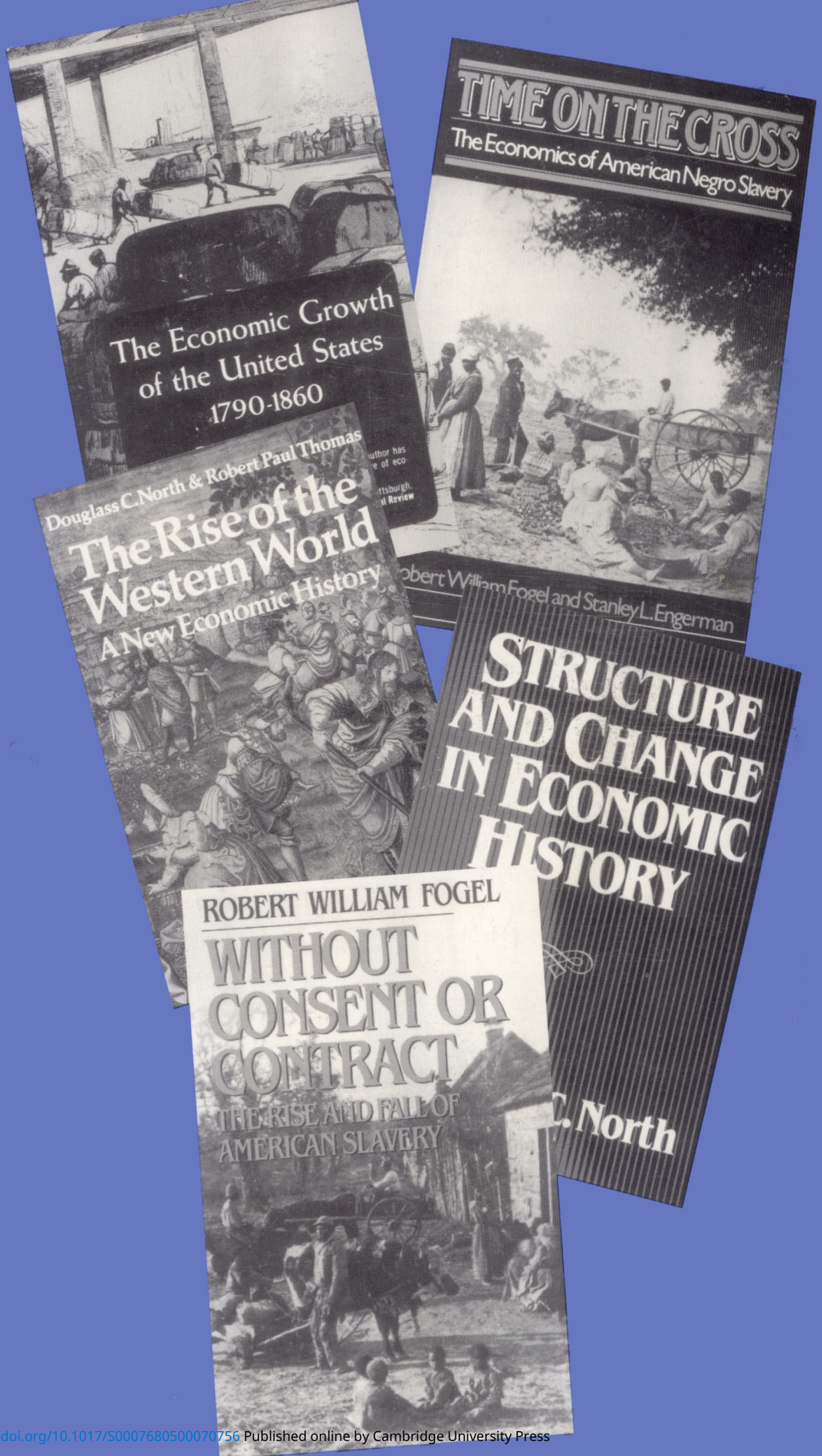

